\section{Case Reports in Neurology}

Case Rep Neurol 2021;13:92-99

DOI: 10.1159/000512324

Published online: February 15, 2021

(c) 2021 The Author(s)

Published by S. Karger AG, Base www.karger.com/crn

This article is licensed under the Creative Commons Attribution-NonCommercial 4.0 International License (CC BY-NC) (http://www.karger.com/Services/OpenAccessLicense) Usage and distribution for commercial purposes requires written permission.

\title{
Transcranial Direct Current Stimulation Combined with Botulinum Neurotoxin Type A Injections for Treatment of Upper Limb Intention Tremor in Multiple Sclerosis: A Case Report
}

\author{
Salvatore Facciorusso ${ }^{a} \quad$ Stefania Spina $^{a} \quad$ Luigi Santoro $^{b}$ \\ Nicoletta Cinone ${ }^{b} \quad$ Alessio Baricich ${ }^{c} \quad$ Chiara Ciritella $^{b}$ Pietro Fiore $^{d}$ \\ Andrea Santamato ${ }^{a}, b$, e \\ aSpasticity and Movement Disorders "ReSTaRt" Unit, Physical Medicine and Rehabilitation

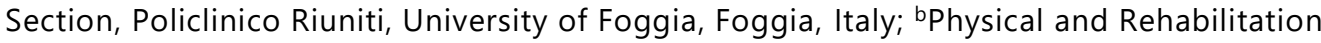 \\ Section, Policlinico Riuniti, Foggia, Italy; 'Physical Medicine and Rehabilitation Unit, \\ University Hospital "Maggiore della Carità," Department of Health Sciences, University of \\ Eastern Piedmont "A. Avogadro", Novara, Italy; 'Neurorehabilitation Unit, ICS Maugeri,

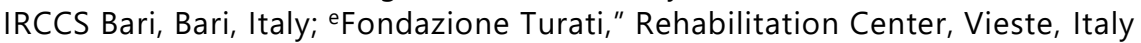

\section{Keywords}

Transcranial direct current stimulation - Botulinum neurotoxin type A · Multiple sclerosis .

Tremor · Surface electromyography

\section{Abstract}

Upper limb intention tremor is a common cause of disability in multiple sclerosis (MS). Transcranial direct current stimulation (tDCS) is an emerging form of brain stimulation used to

\begin{tabular}{ll}
\hline & Andrea Santamato \\
Spasticity and Movement Disorders "ReSTaRt" Unit, Physical Medicine and & Rehabilitation Section \\
"Policlinico Riuniti," University of Foggia \\
Viale Luigi Pinto 1, IT-71122 Foggia (Italy) \\
andrea.santamato@unifg.it
\end{tabular}




\section{Case Reports in Neurology}

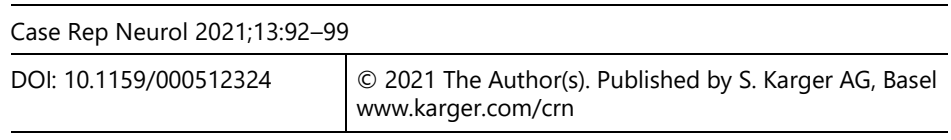

Facciorusso et al.: TDCS and BoNT-A for Treatment of Tremor in Multiple Sclerosis

improve sensorimotor impairments in many neurological disorders. Here, we describe a combined therapeutic approach with botulinum neurotoxin type A (BoNT-A) and tDCS for the treatment of upper limb tremor in a patient with MS. We administered a cathodal tDCS 15 days after the injections of BoNT-A. Both post-injection and post-stimulation evaluation revealed a considerable improvement of the tremor. This approach positively affected the patient's activities of daily living. Our case report shows a safe and beneficial effect of tDCS in the treatment of action tremor in MS especially as a possible adjunctive synergic treatment with BoNT-A injections.

(C) 2021 The Author(s)

Published by S. Karger AG, Basel

\section{Introduction}

Upper limb intention tremor is a common cause of disability in multiple sclerosis (MS), affecting up to $25 \%$ of patients [1]. Action tremor is defined as "any tremor that is produced by voluntary contraction of muscle, including postural, isometric, and kinetic tremor" [2]. Pharmacological and nonpharmacological interventions have been studied [1]. However, no report investigated the effect of neurostimulation on tremor in MS. A recent review summarized some promising results of noninvasive central and peripheral stimulation for essential tremor [3]. Transcranial direct current stimulation (tDCS) is a kind of noninvasive brain stimulation that can be used to modulate cortical excitability (i.e., a weak cathodal electric current applied to the brain decreases cortical activity). It could induce prolonged yet reversible shifts in cortical excitability and might modulate the connectivity of various neural circuits [4]. Here, we report the first case whose tremor following MS improved after botulinum toxin injections combined with tDCS.

\section{Case Report}

A 59-year-old right-handed man suffered from MS (EDSS 4) with a 3-year history of relapsing-remitting MS. Under therapy with Gilenya, he was clinically stable without new relapses. The patient was able to walk without support with a mild gait deviation on the left side. In order to describe the tremor well, we used a multidimensional assessment of tremor (MAT) [5] that measures the severity and the functional and psychosocial impact of tremor in people with MS. His major motor symptom was an intention, postural and task-related tremor (3-5 $\mathrm{Hz}$ ) on the left side. At rest, no tremor was observed. The patient reported that his tremor made him feel depressed, frustrated, and embarrassed, and that fatigue and stressful events affected his tremor. His tremor severity was 7 on the left upper limb subtotal score. The patient had a severe tremor ( 4 out of 5) on the NARCOMS Tremor and Coordination Scale [6]. On the activities of daily living (ADL) self-questionnaire, he rated 18 out of a maximum of 24 points. On the diadochokinesia scale, he scored 3 (out of 5) for dysdiadochokinesia and 2 (out of 3) for dysmetria with the left upper limb. He scored 0 with his right side [7]. He also showed a few beats of nystagmus in both eyes at horizontal sight. In addition, he showed mild 


\section{Case Reports in Neurology}

Case Rep Neurol 2021;13:92-99

DOI: $10.1159 / 000512324$ (c)

(C) 2021 The Author(s). Published by S. Karger AG, Basel www.karger.com/crn

Facciorusso et al.: TDCS and BoNT-A for Treatment of Tremor in Multiple Sclerosis

dysarthria. A mild muscular strength reduction was found in the left upper and lower extremity (Manual Muscle Test 4 out of 5 points). A more specific assessment of the upper limb function included the Box and Block Test and the 9-Hole Peg Test. The patient completed both tests with the right and the left hand. A surface electromyography (sEMG) was performed mainly to identify the muscle to be injected and to characterize tremor. sEMG electrodes (FreeEEEMG1000; BTS Bioengineering, Milan, Italy) were positioned on six muscles of the left upper limb: deltoideus anterior, infraspinatus, biceps brachii, triceps brachii, flexor carpi radialis, and extensor digitorum. The electrode position and orientation were located and marked according to the SENIAM guidelines. Recording was made with the patient in a sitting position during an anterior reaching task (Fig. 1). sEMG recordings of the muscles examined showed 3- to 4-Hz biceps/triceps synchronous action tremor and 4- to 5-Hz flexor carpi/extensor digitorum alternating action tremor and no involuntary activity during rest. The mean amplitude during 4 consecutive reaching movement was calculated (see Table 1 for details).

At the first assessment, sEMG recordings of the muscles examined showed a pattern of abnormal intermittent and continuous activity (Fig. 1a). Following the baseline evaluation (pre-treatment), we scheduled a first follow-up evaluation 15 days post injections (post botulinum neurotoxin type A [BoNT-A]) and second follow-up evaluation just after the last tDCS session (post BoNT-A plus tDCS). We injected 1,000 $\mathrm{U}$ of abobotulinumtoxin diluted in $1 \mathrm{~mL}$ of preservative-free normal saline using a 1-mL syringe and a 26-gauge needle into the agonist and antagonist muscles of the left wrist, elbow, and shoulder (Table 1). A B-mode ultrasound guide was used for precise localization of muscle injection. After the follow-up evaluation (15 days after injections), the patient underwent a cycle of 15 sessions ( $25 \mathrm{~min}$; 5/week) of cathodal tDCS applied on the area representing the primary motor cortex (contralateral to tremor) and the anode over the ipsilesional supraorbital area (we used the international 1020 system for a more precise electrode placement [8]). We used a weak direct current (2 mA) delivered by a constant current stimulator (BrainStim, E.M.S. srl, Bologna, Italy) through saline-soaked sponge electrodes $\left(3.5 \mathrm{~cm}^{2}\right)$ attached to a customizable headband and stabilized with a tubular elastic net (Fig. 2). The contralateral area M1 was chosen according to previous studies that identified a relationship with essential upper limb tremor [9]. After BoNT-A injections, the patient reported a partial regression of his tremor symptom. In particular, 9 HPT showed a $15.5 \%$ reduction and BBT showed $46.6 \%$ of improvement. Moreover, sEMG recordings showed a reduction of both distal and proximal arm muscle activity, although the frequency and burst pattern of tremor remained unaffected (Fig. 1b). Then, after the tDCS cycle, we found an adjunctive improvement at hand dexterity tested with 9HPT and BBT (Table 2). The subjective score of the ADL questionnaire improved from 16 to 11 after botulinum toxin injection and from 11 to 8 after tDCS intervention. Additionally, the patient improved on the other outcomes examined (Table 2). After BoNT-plus tDCS treatment, the sEMG signals showed a further reduction of muscle activity and an improvement of activation pattern and timing (Fig. 1c). We also noted a reduction in mean amplitude in all muscles after both single and combined treatment (see details in Table 1). 


\section{Case Reports in Neurology}

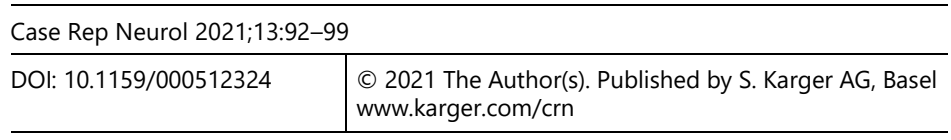

Facciorusso et al.: TDCS and BoNT-A for Treatment of Tremor in Multiple Sclerosis

\section{Discussion}

The symptomatic treatment of MS tremor is one of the most challenging goals for clinicians. Intention tremor is a disabling condition in MS patients affecting a variety of daily activities [10]. Many strategies to treat this symptom were reported in the literature, but evidence is conflicting [1The use of non-invasive brain stimulation to treat essential tremor is wellknown and has shown promising results [3]. However, to our knowledge, this is the first case report that indicates the beneficial effect of inhibitory tDCS in combination with botulinum toxin injection on improving upper limb tremor of an MS patient. On the other hand, the use of BoNT-A in the treatment of intention tremor in MS was investigated in a few studies. Van der Walt et al. [11], reported a significant reduction in tremor severity following BoNT-A treatment compared with placebo group in 33 MS patients. More recently, another randomized study confirmed these results in 43 MS patients demonstrating an improvement in clinical upper limb tremor severity after BoNT-A injections and showing an additional therapeutic effect due to neuroplastic changes to the brain [12].

Nowadays, there are a large number of non-pharmacological tools for treating the clinical picture in MS $[13,14]$. Thus, there is a growing demand to create combined treatment protocols, with pharmacological and non-pharmacological therapy, to achieve the best possible outcome in people with MS. Our patient reported an improvement in dexterity and tremor severity which had a beneficial impact on his ADL and his psychosocial factors as shown in the MAT. In our case, the sEMG analysis confirmed the clinical improvements with a reduction of mean amplitude and a better pattern of activation both after BoNT-A injections and after BoNT-A plus tDCS during a reaching task. A randomized, double-blind, crossover study found that motor tDCS might improve hand dexterity in MS patients [15]. According to these findings, we proposed two possible effects of cathodal tDCS on our patient's condition to explain these positive outcomes. The first may be that cathodal current might directly modulate the activity of the upper limb area of the motor cortex, improving upper limb functions and hand dexterity. The second indirect effect might enhance brain reorganization due to BoNT-A. In the future, further study with functional neuroimaging could be able to support this hypothesis.

In the present case report, the patient reported a slight improvement in intention tremor with combined treatment. The dosage and location of BoNT-A administered in this study did not result in any severe adverse effects. The patient complained of only a mild weakness in the extension of the fourth and fifth finger of the left hand. Furthermore, the patient did not report any complication or discomfort related to tDCS.

This is a report of a single patient, so we cannot generalize our results. It is also impossible to exclude that his improvement reflected the stabilization of the effect of botulinum toxin. However, the improvement in all the outcomes investigated after this combined treatment might support our hypothesis that tDCS can improve motor function and reduce intention tremor in MS.

\section{Karger'=}




\section{Case Reports in Neurology}

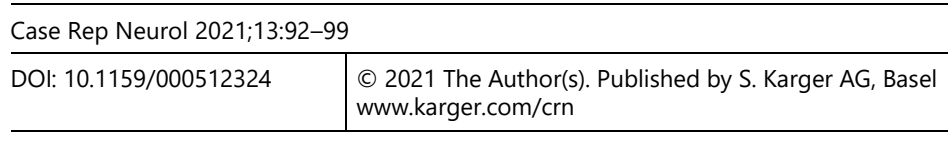

Facciorusso et al.: TDCS and BoNT-A for Treatment of Tremor in Multiple Sclerosis

\section{Conclusion}

These results suggest that combined treatment with botulinum injections and a cathodal tDCS applied over the contralateral motor area could be a useful and safe therapeutic strategy for intention tremor in MS. With this case report, we suggest a synergistic therapeutic approach using emerging knowledge in neuroplasticity and neurorehabilitation.

\section{Statement of Ethics}

This article was conducted ethically in accordance with the World Medical Association Declaration of Helsinki. The subject in this paper gave written informed consent for publication of his case including publication of images. All authors read and approved the final version of the manuscript.

\section{Conflict of Interest Statement}

The authors have no conflicts of interest to declare.

\section{Funding Sources}

There was no funding.

\section{Author Contributions}

S. Facciorusso designed the study and wrote the original draft, analyzed and interpreted the data and reviewed the manuscript. S. Spina contributed to the management of the patient, analysis and interpretation of the data, preparation, and review of the manuscript. N. Cinone and L. Santoro contributed to images, description drafting, and critically reviewing the manuscript. P. Fiore, A. Santamato, A. Baricich, and C. Ciritella contributed to drafting the manuscript. All authors read and approved the final version of the manuscript and ensured that questions related to the accuracy or integrity of any part of the work are appropriately investigated and resolved.

\section{References}

1 Koch M, Mostert J, Heersema D, De Keyser J. Tremor in multiple sclerosis. J Neurol. 2007 Feb;254(2):133-45.

2 Bain PG. The management of tremor. J Neurol Neurosurg Psychiatry. 2002 Mar;72 Suppl 1(Suppl 1):I3-I9. doi: 10.1136/jnnp.72.suppl_1.i3.

\section{Karger'=}




\section{Case Reports in Neurology}

\begin{tabular}{l|l}
\hline Case Rep Neurol 2021;13:92-99 \\
\hline DOI: 10.1159/000512324 & $\begin{array}{l}\text { (C) 2021 The Author(s). Published by S. Karger AG, Basel } \\
\text { www.karger.com/crn }\end{array}$ \\
\hline
\end{tabular}

Facciorusso et al.: TDCS and BoNT-A for Treatment of Tremor in Multiple Sclerosis

3 Kang N, Cauraugh JH. Does non-invasive brain stimulation reduce essential tremor? A systematic review and meta-analysis. PLoS One. 2017 Sep;12(9):e0185462.

4 Nitsche MA, Paulus W. Excitability changes induced in the human motor cortex by weak transcranial direct current stimulation. J Physiol. 2000 Sep;527(Pt 3):633-9.

5 Daudrich B, Hurl D, Forwell S. Multidimensional Assessment of Tremor in Multiple Sclerosis. Int J MS Care. 2010;12(1):23-32.

6 Marrie RA, Goldman M. Validation of the NARCOMS Registry: Tremor and Coordination Scale. Int J MS Care. 2011;13(3):114-20.

7 Alusi SH, Worthington J, Glickman S, Findley LJ, Bain PG. Evaluation of three different ways of assessing tremor in multiple sclerosis. J Neurol Neurosurg Psychiatry. 2000 Jun;68(6):756-60.

8 Klem GH, Otto Lu Èders H, Jasper H, Elger C. The ten-twenty electrode system of the International Federation. The International Federation of Clinical Neurophysiology. Electroencephalogr Clin Neurophysiol Suppl. 1999;52:3-6.

9 Neely KA, Kurani AS, Shukla P, Planetta PJ, Shukla AW, Goldman JG, et al. Functional Brain Activity Relates to 0-3 and 3-8 Hz Force Oscillations in Essential Tremor. Cereb Cortex. 2015 Nov;25(11):4191-202. doi: $10.1093 /$ cercor/bhu142.

10 Feys P, Romberg A, Ruutiainen J, Ketelaer P. Interference of upper limb tremor on daily life activities in people with multiple sclerosis. Occup Ther Health Care. 2004;17(3-4):81-95.

11 Van Der Walt A, Sung S, Spelman T, Marriott M, Kolbe S, Mitchell P, et al. A double-blind, randomized, controlled study of botulinum toxin type A in MS-related tremor. Neurology. 2012 Jul;79(1):92-9.

12 Boonstra FM, Evans A, Noffs G, Perera T, Jokubaitis V, Stankovich J, et al. OnabotulinumtoxinA treatment for MS-tremor modifies fMRI tremor response in central sensory-motor integration areas. Mult Scler Relat Disord. 2020 May;40:101984.

13 Etoom M, Khraiwesh Y, Lena F, Hawamdeh M, Hawamdeh Z, Centonze D, et al. Effectiveness of Physiotherapy Interventions on Spasticity in People With Multiple Sclerosis: A Systematic Review and MetaAnalysis. Am J Phys Med Rehabil. 2018 Nov;97(11):793-807.

14 Iodice R, Manganelli F, Dubbioso R. The therapeutic use of non-invasive brain stimulation in multiple sclerosis - a review. Restor Neurol Neurosci. 2017;35(5):497-509.

15 Ayache SS, Riachi N, Ahdab R, Chalah MA. Effects of transcranial direct current stimulation on hand dexterity in multiple sclerosis: A design for a randomized controlled trial. Brain Sci. 2020 Mar;10(3):E185. 


\section{Case Reports in Neurology}

\begin{tabular}{l|l} 
Case Rep Neurol 2021;13:92-99 \\
\hline DOI: 10.1159/000512324 & $\begin{array}{l}\text { (c) } 2021 \text { The Author(s). Published by S. Karger AG, Basel } \\
\text { www.karger.com/crn }\end{array}$ \\
\hline
\end{tabular}

Facciorusso et al.: TDCS and BoNT-A for Treatment of Tremor in Multiple Sclerosis
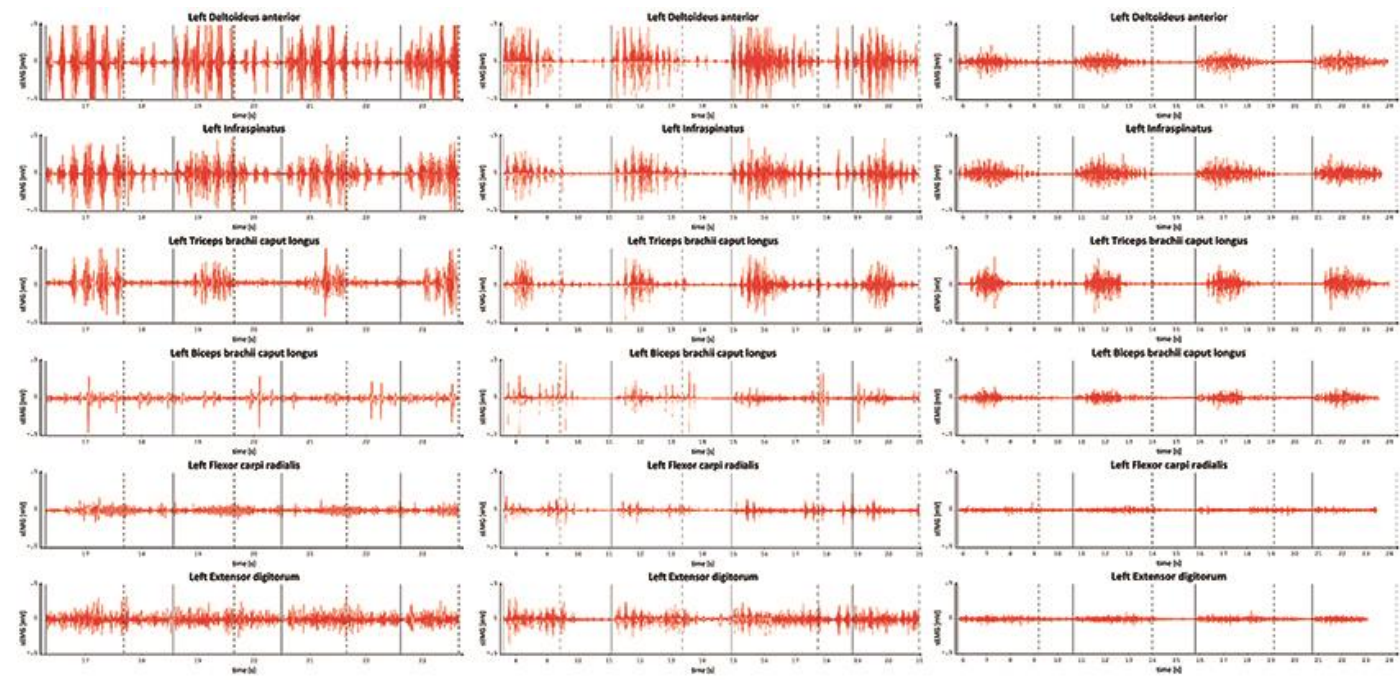

(2) Nevertment

Mpeseroutat

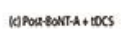

Fig. 1. Electromyographic recordings during a reaching task before treatment (a), after botulinum toxin injections (b), and after combined treatment (botulinum toxin injections and tDCS) (c). The vertical continuous line shows the beginning of the task, the vertical dashed line shows the return to the starting position. sEMG, surface electromyography; tDCS, transcranial direct current stimulation; $\mathrm{mV}$, millivolt; $\mathrm{s}$, seconds. Low-pass filter, $250 \mathrm{~Hz}$; high-pass filter, $20 \mathrm{~Hz}$.

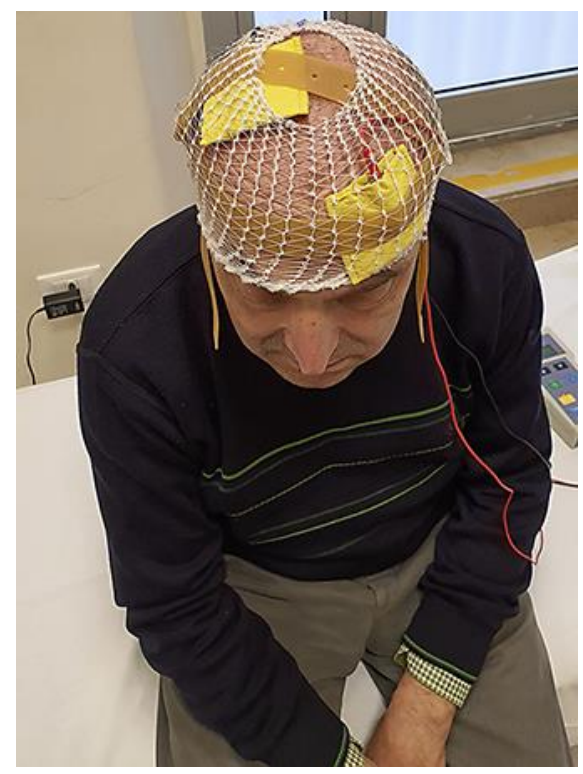

Fig. 2. Electrode placement over the scalp of the patient. 


\section{Case Reports in Neurology}

\begin{tabular}{l|l}
\hline Case Rep Neurol 2021;13:92-99 \\
\hline DOI: 10.1159/000512324 & $\begin{array}{l}\text { (c) 2021 The Author(s). Published by S. Karger AG, Basel } \\
\text { www.karger.com/crn }\end{array}$ \\
\hline
\end{tabular}

Facciorusso et al.: TDCS and BoNT-A for Treatment of Tremor in Multiple Sclerosis

Table 1. Dosage and localization of injected muscles, and mean amplitude of sEMG signals during a reaching task (four consecutive trials)

\begin{tabular}{lcllll}
\hline Muscles (left) & Dosage, $U$ & $\begin{array}{l}\text { Sites } \\
\text { injected, } n\end{array}$ & $\begin{array}{l}\text { Mean amplitude } \\
\text { pre-treatment, } \\
\mathrm{mV} \pm \mathrm{SD}\end{array}$ & $\begin{array}{l}\text { Mean amplitude } \\
\text { post BoNT-A, } \\
\mathrm{mV} \pm \text { SD }\end{array}$ & $\begin{array}{l}\text { Mean amplitude } \\
\text { post BoNT-A + tDCS, } \\
\mathrm{mV} \pm \text { SD }\end{array}$ \\
\hline Deltoideus anterior & 150 & 1 & $0.128 \pm 0.153$ & $0.083 \pm 0.209$ & $0.029 \pm 0.029$ \\
Infraspinatus & 200 & 2 & $0.089 \pm 0.086$ & $0.056 \pm 0.062$ & $0.034 \pm 0.040$ \\
Biceps brachii & 150 & 1 & $0.038 \pm 0.048$ & $0.032 \pm 0.037$ & $0.022 \pm 0.021$ \\
Triceps brachii & 200 & 2 & $0.058 \pm 0.074$ & $0.045 \pm 0.066$ & $0.042 \pm 0.059$ \\
Flexor carpi radialis & 150 & 1 & $0.033 \pm 0.031$ & $0.019 \pm 0.021$ & $0.012 \pm 0.011$ \\
Extensor digitorum & 150 & 1 & $0.060 \pm 0.053$ & $0.041 \pm 0.034$ & $0.016 \pm 0.014$ \\
Total & 1,000 & 7 & & & \\
\hline
\end{tabular}

tDCS, transcranial direct current stimulation; BoNT-A, botulinum neurotoxin type A; sEMG, surface electromyography; mV, millivolt; SD, standard deviation; $\mathrm{U}$, unit; $n$, numbers.

Table 2. Score of the outcome measures applied before BoNT-A treatment, after 15 days from injections (before the brain stimulation) and after the brain stimulation

\begin{tabular}{|c|c|c|c|c|c|c|}
\hline \multirow[t]{2}{*}{ Outcome measures } & \multicolumn{2}{|c|}{ Pre BoNT-A } & \multicolumn{2}{|c|}{ Post BoNT-A } & \multicolumn{2}{|c|}{ Post BoNT-A + tDCS } \\
\hline & right & left & right & left & right & left \\
\hline 9HPT, s & 31 & 138 & 34 & 118 & 30 & 105 \\
\hline BBT & 32 & 15 & 30 & 22 & 30 & 28 \\
\hline NARCOMS & 0 & 4 & 0 & 3 & 0 & 2 \\
\hline Tremor severity score (left UL) & 0 & 7 & 0 & 5 & 0 & 4 \\
\hline ADL & - & 16 & - & 11 & - & 8 \\
\hline Dysdiadochokinesia scale & 0 & 3 & 0 & 2 & 0 & 2 \\
\hline Dysmetria scale & 0 & 2 & 0 & 2 & 0 & 2 \\
\hline
\end{tabular}

9HPT, 9 Hole Peg Test; ADL, Activities of Daily Living questionnaire; UL, upper limb; tDCS, transcranial direct current stimulation; BoNT-A, botulinum neurotoxin type A. 